\title{
Teaching Leadership in the EMBA: Where to Begin
}

Priscilla Berry, Jacksonville University, USA

\begin{abstract}
An examination of the role of a corporate leader versus the role of a corporate manager makes clear the distinct differences. The lines are often blurred in discussion of these executive levels of corporate governance, and individuals in the corporate settings often seek leadership roles without a clear understanding of what the leadership with the capital " $L$ " entails. In addition, individuals seek leadership roles out of the need to be rescued from a management position and are seeking leadership for the wrong reasons. A careful and lengthy process of personal evaluation is a mandate for individuals seeking leadership. Leadership is not a venue for the many, but only for the few and requires more than management expertise.
\end{abstract}

Keywords: leadership; managers; corporate culture; $360^{\circ}$; MBA, self-assessment

\section{INTRODUCTION}

$\mathrm{t}$ is amazing to me over the many years that $\mathrm{I}$ have coached executives and counseled students how the thread of seeming discontent remains so much the same, even though the business world has changed dramatically. People want to have a voice, and they want to be heard. It's archetypal, it's seminal, it's core, it's key, and it is all about communication. Managers look at their leaders in the corporate environment and they believe they are as smart or smarter than what they see. This realization takes one of two paths for them; either they seek the leadership roles in these corporations, or they intend to take their MBAs and move into the role of entrepreneur, feeling powerless to change the structure or culture inside the organization, as they continue to feel overlooked and ineffective. The caveat that I would impart for the would-be seekers of leadership is to make sure to be ready before you step out or seek to step up into corporate leadership. Please note that when this monologue references leadership, it is with the capital " $\mathrm{L}$ " and is reference to the positions of complete and total accountability, rather than a reference to the leaders whom we all must be in our homes and in our communities.

\section{HOW TO KNOW IF LEADERSHIP IS FOR YOU}

First, we need to examine what it means to be ready and how to know if this is the path for you. Many people are frustrated, not because they need leadership roles to have a voice, but because they are underemployed; and there is a big difference. The assessment of being ready for leadership has to begin with an analysis of where you are and of who you really are. You may be a capable manager and just in the wrong place within the company or even in the wrong industry. You will not fix this problem by seeking a leadership role. Many frustrated managers are simply seeking a leadership role because they are undervalued for their job performance within the company, because they need more training in their own job function, or they lack the staff support or resources to perform the job function to which they are assigned. This is not the motivation one needs to seek a leadership position. It would be valuable for the would-be-leader to reassess the job function in terms of real needs rather than believing that a leadership role would make the difference in job performance outcomes or personal satisfaction.

Second, to know if what you are seeking is a leadership role for yourself, you must begin with selfassessment. We say in business that it is important to know who is coming to the table; well, the most important person coming to the table is always You! Every MBA program proclaims the importance of self-assessment. Every leader on the fore front of accountability, transparency, and peace-making within their corporation today says how important the Socrates version of "know thyself" plays out into reality. The Greek philosopher said, "The 
unexamined life is not worth living." Shakespeare says, "To thine own self be true, and it cannot help but follow as the day the night, thou canst' not then be false to any man." Historically and in the moment, we recognize the power and force of knowing who we are before we begin to lead others. This type of deep introspection is not possible for everyone and not something from which a front line manager may necessarily derive benefit. Remember that corporations must employ many high powered and high performing managers who are always in the process of seeing that things are done right for the corporation. However, individuals who are definitely on the leadership path or in a succession plan for a leadership role within the corporate structure must be willing to take the plunge into real self-analysis.

Jose' Almeida, the head of Covidien's medical device division, in an interview with Alan Rappeport, said, "If I know who I am, I manage people better." He goes on to explain, "When I'm faced with an integrity issue and I have to take disciplinary action on somebody, I know why I think the way I think. It's very personal." (Rappeport, Financial Times, Business Education, May 10, 2010, p. 20). When you have been and are involved with this type of self-awareness, then your decision-making process is much easier, and you are much more comfortable making the hard calls.

I would also suggest that if you are not comfortable with self-assessment and you are not postured to receive, then you are not ready for a leadership role. It is really okay, too, since we need more Indians than chiefs. If you are frustrated where you are, make sure that you are not confusing the desire for a leadership command post with just being under valued as a manager. Years ago, the phrase was to find the right person for the job; now we say, "find the right job for the person". Being in the "right" place makes the difference in success and failure in job performance and, in that sense, of either personal fulfillment or world ennui.

It is highly involved and the subject of debate, but real self-analysis can require something more than $360^{\circ}$ evaluations or profiles, like the Myer-Briggs Type Indicator. While these are strong indictors of the profile required for leadership and should be some of the arrows in the quiver, there are other psychological studies that point to the determiners for leadership capacity. For anyone serious about selecting the leadership pipe line, being open to psychological profiling can be profitable. There is a high predictability for who can and should lead. When Collins and many others write of the notable leaders of corporate America, it is clear that the surface personalities may not always look the same, but the similarities are strikingly the same in the way they think (Collins, 2001). Neuroscientists suggest that there are brain patterns that are distinct in individuals who have been and are in leadership roles, just as there are specific brain patterns of mass murders. The brains of leaders are different from the aggregate population and almost always have more analytical capacity. The distinctions are multiple for individuals who are leaders as opposed to managers (Dickmann, 2002).

\section{ACKNOWLEDGING THE DIFFERENCES}

Managers are the core of how we get work done and must be valued for doing things right. Corporations cannot function without empowered managers who are loyal to the company and who demonstrate a high level of emotional intelligence to make decisions in the best interest of themselves and the corporation. It is critical for the growth of the corporate bottom line that managers are nurtured and rewarded and that they are given resources for professional growth and development. They must "feel" valued in their role and they should not be directed into seeking leadership roles when this is not what they need or what they actually want in their career, nor are they willing to allow it to be part of their personal commitment. So often people who think they want leadership roles are unclear about what kind of commitment and responsibility leadership entails and how co-dependent management and leadership have to be. One cannot survive without the other.

Leadership profiles are different than the profiles of a manager and the classic pattern of managers doing things right and the leaders doing the right things places the burden of total accountability on the leader. It is a 24/7 job in your head and often on your feet as well. Jim Collins, in his book Good to Great, discusses the level-five leaders and explains the difference in the leadership in companies that have become great. While his text is now dated in terms of current role models, his research data remains valid in that with all the variations in industry, size, and product of these great companies, the leaders of these companies had one thing in common. They were 
individuals who were more alike than different and they were not the charismatic savior-type people, but rather individuals who were, while ambitious, ambitious for the company first (Collins, 2001).

As an anecdote, I hired a manager for my home, who was from Northern Italy, and for many years, she cooked for me and ran the house, and I ate healthier and happier in that period than I have in my life. I watched how she worked and how she thought, and I ate what she delivered. She woke up thinking food, and her last thoughts at night were what ingredients she needed for the next gastronomical experience she wanted to create. She was doing what she loved, and, in part, her success was the result of how she thought, not just of what she knew how to do. It was always about the food! She had the pictures always in her mind.

Leaders need to be happily disposed to enjoy always thinking strategy and organizational behavior in order for their followers to enjoy what they deliver. If a person has to work at creating the picture of how things should be, it is too much effort. It must be a natural process and feel right, in that, life is more about feelings than facts. You must go to bed and wake up thinking how to make the corporation successful and employees successful and these thoughts must feel right.

If you are thinking strategy for your corporation or driving business performance or creating the environment for change, it must be the kind of performance that not only works and brings tangible results, but, more importantly, it has to be a fit for you. Too many managers think they want to go into leadership roles when what they are really feeling is the lack of connection from the work and the lack of voice in the procedure. This is not at all a call to seek leadership.

Functional units are led by managers who must perform at high levels to produce results and the deliverables for the unit. These managers must understand how everything works in their unit and all the idiosyncrasies associated with the personnel and how to meet all their needs. They must at least understand the overall corporate mission, but their accountability has to be with their unit. They are not required to look at or assume responsibility for the overall performance of the corporation. It is essential for managers to believe and know that their work is essential to the progress of the whole and that if the unit is not successful, the corporation is weaker.

However, managers are not tasked with the responsibility for sustainability, corporate innovation, or performing in the global economic crisis. Managers are not removed from this knowledge, nor are they less impacted by these elements; but they are not responsible for manipulating these forces and setting the strategy for creating the vision that takes the company past the siren song.

Like it or not, managers must operate much of the time in silos, which is why so much MBA education works because we are teaching, for the most part, managers who are accustomed to silo performing and, therefore, silo learning is not foreign to them. Students in search of real leadership roles are the most critical about the silo learning in MBA programs and the compartmentalization of course work without any program that really connects the dots to leadership (Datar, Garvin \& Cullen, 2010).

\section{WHY ONLY THE LEADER IS THE ONE}

For sure, we need managers throughout the company who can lead their people and are empowered to make decisions. This is not the same as the leaders who are responsible for the direction of the entire ship or the total mission.

I disagree with Leonard Schlesinger, President of the Babson College of Business near Boston, granted the business college's entire focus is entrepreneurship. He compares Obama's leadership to being a successful entrepreneur in his article Entrepreneurship-in-Chief. He says, "Many typically see entrepreneurs as business founders and, indeed, many are. But we believe that successful entrepreneurs make and find opportunities in any setting -- a start-up, family enterprise, corporate business or not-for-profit. They have a restless passion for making change and finding a better way." He is making a case that the President is an entrepreneur (Benson \& Schlesinger March 7, 2009). 
The entrepreneurial spirit and the entrepreneur must be separated and so often, the two separate animals are slurred together. Every manager and every leader must have an entrepreneurial spirit that drives them to be creative and seek new ideas and find new paradigms; but we do not need leaders who are always seeking ideas or something outside to solve the problems. When problems occur, the first place the leader must look is inside, not outside. The spirit of the entrepreneur compels people to look outside and to always be driving to start their own business and run it their way. This passion is a wonderful thing and helps to make America great!

Individuals who seek to be entrepreneurs in the classical sense are those individuals who desire to leave the confines of the corporate environment. So, in Schlesinger's list, I leave most of his entities intact, but omit corporate business as the place for the entrepreneur. In fact, a look at Schlesinger's background shows that he learned most of what he knows about the business arena from being in the corporate world and not from start-up business.

We do not want or need the drive or the mentality that are required of a start-up business in the corporate setting. It is an entirely different animal. It just sounds good to include in Schlesinger's list, and it is a rather different expression. In reality, the entrepreneur, in a corporate setting, may becomes a liability because he or she is always looking for ways to exit and to form their own world. They often cannot sustain a leadership role because they do not seek longevity within the company. They are not tied to the vision of the corporation so much as committed to leaning all they can and absorbing the training and experiences that are possible and eagerly awaiting the perfect opportunity to exit. This is truly an American phenomenon and one that makes the fabric of our business world and our system of capitalism very rich, but it is not the breeding ground for corporate leadership. In fact, it may be some of the negative spirit that has driven or motivated many of the leaders in corporate scandals because the spirit is single-minded and focused on personal achievement rather than the concept that if we make it, we will make it together.

It is the leader who must have the holistic view and the manager serves the greater purpose by delivering a high level of performance at a level that brings clarity to the larger mission, but does not drive the ship. It is important to have managers who can analyze, but you must have the leader who can pull the trigger. Once Abraham Zaleznik (in 1977) opened the discussion in his Harvard Business Review article on the distinction between managers and leaders, the dialogue has been continuous about this distinction (Zaleznik, 1977).

Zaleznik said (and really for the first time in business literature):

What it takes to ensure a supply of people who will assume practical responsibility may inhibit the development of great leaders. On the other hand, the presence of great leaders may undermine the development of managers who typically become very anxious in the relative disorder that leaders seem to generate (p. 75).

He goes on to say that managers are not like leaders in that their histories are different, their career paths to power are not the same, and their Myers-Briggs is not the same (Zaleznik, 1977). Actually, he did not say their Myers-Briggs is not the same, but it is not; managers see the world in very different ways than leaders and process information in very different ways than leaders. Managers are caught up in getting the job done and can tolerate a great deal more of the mundane, while leaders can barely manage the idea of physically collating a document; and if challenged or forced into the mundane, will not survive and certainly will not be productive. Someone has to be in the weeds, but not the Leader.

\section{MANAGERS AND LEADERS: THE CASE FOR BOTH}

John Kotter, in his book, What Leaders Really Do, makes rather clear the distinction between managers and leaders, while stating the obvious, which is that we must have both for any corporation to succeed. Kotter says, "Managers promote stability, while leaders press for change, and only organizations that embrace both sides of that contradiction can thrive in turbulent times"(1999, pp. 52-53). Corporations should not try to promote all the managers into leadership roles; it is not productive for the company and not positive for the manager. Keep in mind that Kotter is writing this piece in 1999 and making the observation that in the United States, most corporations are "overmanaged and underled"(p. 51). It would be an understatement that he was a voice ahead of and in forecast of 
the scandals in failed leadership that have surfaced in the first part of the $21^{\text {st }}$ century. It is now evident that we had individuals who were ambitious for their own profit, who were in leadership roles in some of these failed corporate structures, but what we did not have is real leaders.

There is currently a failure in leadership and a resounding loss of leadership in the first part of the $21^{\text {st }}$ century, for sure; but corporations should not do all the mining for leadership in the ranks of managers, nor assume that all their managers should be leaders. Managers should be given the opportunity for leadership training, but not make the assumption that a leadership position will correct the culture, cure the problems with management, or meet their personal needs of validation. Managers who are in leadership roles and not vetted properly for these positions will quickly become a liability, not just for themselves, but most definitely for the company. Having strong leadership with weak management is a receipt for disaster and managers should not see the leadership position as a solution for their management challenges.

One reason that we often cannot always seek leaders from the ranks of management and that managers are not always suited for leadership is addressed by Chris Argyris in the classic, Teaching Smart People to Learn. Leaders are individuals who have been schooled in the trenches, not only of success, but also of failure. Part of the problem with many managers is that they came right out of academic success and joined a company in management training where they are again completely at the top of the class. They have not experienced, personally, plans or strategy that failed and, while they have great institutional knowledge that is valuable, they have not experienced professional and thus personal loss which is an essential ingredient for the leadership profile (1991).

\section{CONCLUSION}

It is essential that there is a clear distinction between managers and leaders and that their roles are clear and equally valued. One is not a substitute for the other; one cannot be strong and the other weak and have a profitable company. Companies that make the distinction between leadership and management and value both equally are the companies that represent the Collin's brand of good to great. Managers must understand that seeking a leadership role is not a personal path to greatness and that cultivating managerial strength is vital to the corporate mission. Respecting and valuing the role of both leaders and managers, and recognizing the distinct differences, will bring the harmony, accountability, and transparency that companies require for the corporate alignment that is essential for shaping the success of $21^{\text {st }}$ century companies.

\section{AUTHOR INFORMATION}

Dr. Priscilla Berry has a private communications consulting practice: Berry and Associates, which provides businesses with specialized programs to assist with corporate cultural transformation and leadership development, solving internal and public communication challenges. Dr. Berry is a graduate of the University of Mississippi with degrees in English, Literature, and Humanities. She began her career in academia as a professor of literature and writing, but was recruited by local corporations to work on the development and facilitation of communication systems. Dr. Berry is currently researching, publishing, and speaking on women's careers and women in leadership as well as other business and pedagogical subjects.

\section{REFERENCES}

1. Argyris, C. (May, 1991). Teaching Smart People to Learn. Harvard Business Review. Harvard Business School Publishing.

2. Benson, C. \& Schlesinger, L. (March, 7, 2009). Entrepreneur-in-Chief? Commentary: Obama shows signs of understanding innovation process. Wall Street Journal, Market Watch, Outside the Box.

3. Collins, J. (2001). Good to Great: Why Some Companies make the Leap... and others Do Not. HarperCollins.

4. Datar, S., Garvin, D. \& Cullen, P. (2010). Rethinking the MBA: Business Education at a Crossroads, Boston: Harvard Business School Publishing.

5. Dickmann, M.H. \& Stanford-Blair, N. (2002). Connecting Leadership to the Brain. California: Corwin Press. 
6. $\quad$ Kotter, J. (1999). What Leaders Really Do. (a Harvard Business Review Book): USA.

7. Rappeport, A. (May 10, 2010). A Direct, Decisive Leader, Financial Times Business Education: Executive Education Ranking 2010, Paper Supplement,pp.17-20.

8. Zaleznik, A. (1977). Managers and Leaders, Are They Different? Best of Harvard Business Review, pp. 7481.

\section{NOTES}

